\title{
CRYSTAL STRUCTURE OF A PERINDOPRIL CYCLIZATION PRODUCT, $\mathrm{C}_{19} \mathrm{H}_{30} \mathrm{~N}_{2} \mathrm{O}_{4}$
}

\author{
JOANNA BOJARSKA ${ }^{a}$,WALDEMAR MANIUKIEWICZ ${ }^{a}$, MAREK L. GEÓWKA ${ }^{a}$, LESEAW SIERON ${ }^{a}$, MILAN REMKO
}

\begin{abstract}
anstitute of General and Ecological Chemistry, Faculty of Chemistry, Lodz University of Technology, Zeromskiego 116, 90-924 Lodz, Poland ${ }^{b}$ Department of Pharmaceutical Chemistry, Faculty of Pharmacy, Comenius University Bratislava, Odbojarov10, SK-832 32 Bratislava, Slovakia
\end{abstract} (Received: March 15, 2012 - Accepted: June 18, 2012)

\begin{abstract}
The title compound is a product of perindopril intramolecular cyclization. It crystallizes in the tetragonal, non-centrosymmetric space group $P 4{ }_{1} 22_{1}$ (No. 92$)$ with $a=9.3574(2), b=9.3574(2), c=45.6369(9) \AA, \mathrm{V}=3996.01(14) \AA^{3}$ and $\mathrm{Z}=8$. The crystal consists of one molecule in the asymmetric unit. The packing exhibits weak intermolecular $\mathrm{C}-\mathrm{H} \cdots \mathrm{O}=\mathrm{C}$ contacts forming two $C(5)$ and $C(10)$ chains, which together result in graph-set descriptor $R_{3}^{3}(18)$ motif, running along the crystallographic $a$-axis.
\end{abstract}

Keywords: crystal structure, X-ray diffraction, perindopril

\section{INTRODUCTION}

Angiotensin-converting enzyme (ACE) inhibitors are used in therapy of cardiovascular disfunctions. ${ }^{1}$ One of the most common ACE inhibitors on the market is perindopril, $((2 S, 3 \mathrm{a} S, 7 \mathrm{a} S)-1-[(2 S)-2-[[(2 S)$-1-ethoxy-1-oxopentan2-yl]amino]propanoyl]-2,3,3a,4,5,6,7,7a-octahydroindole-2 carboxylic acid (1), used as an antihypertensive drug utilized in the treatment of high blood pressure and heart failure. ${ }^{2}$ In the liver and plasma the perindopril is de-esterified by esterases to its active metabolite - the respective diacid - perindoprilat Contrary to other ACE-inhibitors, it has a higher tissue affinity for the angiotensin-converting enzyme. ${ }^{3}$ Clinically useful forms of perindopril are its tert-butylamine (perindopril erbumine) or $L$-arginine (perindopril $L$-arginine) salts, which were mentioned for the first time in respective patents a decade ago. ${ }^{4,5,6}$ Although perindopril was first reported in $1982,{ }^{7}$ no details were given on its crystal structure. However, the crystal structure of perindoprilat solvate with ethanol was revealed in $1991 .^{8}$ Also three crystal structures, of a hydrate of perindoprilat, of an erbumine salt and its hydrate have been determined in our laboratory. 9,10

The cyclization of dipeptides to diketopiperazines is a well-known phenomenon, being a major stability issue of many ACE inhibitors. ${ }^{11}$ Perindopril may undergo the appropriate degradation reaction (Scheme) during the manufacturing and formulation processes, which is undesirable due to high toxicity of the product. ${ }^{12}$ Now we have determined the crystal structure of the perindopril cyclization product, ethyl (2S)-2-[(3S,5aS,9aS,10aS)-3methyl-1,4-dioxo-5a,6,7,8,9,9a,10,10a-octahydro-3H-pyrazino[1,2-a]indol-2yl]pentanoate.
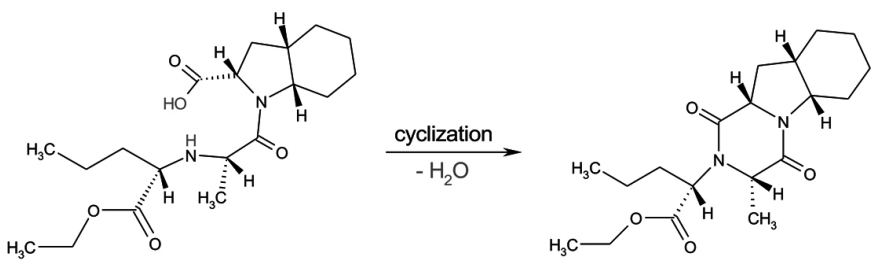

General scheme of perindopril intramolecular cyclization to $\mathbf{1}$.

\section{EXPERIMENTAL}

Well shaped, colourless plate monocrystals suitable for X-ray analysis were grown by slow evaporation from a nitrobenzene solution of the title compound at room temperature.

The crystal structure of (1) was determined by single-crystal X-ray diffraction method from the data collected on the Bruker AXS Smart APEXII CCD 3-circle diffractometer (equipped with MonoCap capillary). The absorption correction was applied using semi-empirical methods of SADABS program. ${ }^{13}$ Data collection and reduction were done with SMART and SAINTPLUS programs. ${ }^{14,15}$ The structure was solved by direct methods and refined by the full-matrix least-squares methods on $F^{2}$ with anisotropic thermal parameters for all non-hydrogen atoms to $R=0.0485$. All hydrogen atoms were placed in geometrically idealized positions and constrained to ride on their parent atoms with $\mathrm{C}-\mathrm{H}=0.93-0.97 \AA$ and with $\mathrm{U}_{\mathrm{ico}}(\mathrm{H})=1.2-1.5 \mathrm{U}_{\mathrm{eq}}(\mathrm{C})$. The terminal methyl $(\mathrm{C} 14)$ and ethyl $(\mathrm{C} 18, \mathrm{C} 19)$ groups were disordered over two positions. Both parts of the disordered groups were restrained using DFIX with the C-C and C-O distances of 1.525 and $1.430 \AA$ respectively.

A perspective view of the molecular structure of $\mathbf{1}$ with the atom labels is shown in Figure 1, while the crystal data are summarized in Table 1. The configuration of the molecule is all-S. ${ }^{16}$

For preparing figures and the geometrical calculations, Mercury and PLATON programs were used. ${ }^{17,18}$

Table 1. Crystal data and details of the structure determination for $\mathbf{1}$.

\begin{tabular}{|c|c|}
\hline Crystal data & \\
\hline $\mathrm{C}_{19} \mathrm{H}_{30} \mathrm{~N}_{2} \mathrm{O}_{4}$ & $Z=8$ \\
\hline$M r=350.45$ & $\mathrm{Cu} K \alpha$ radiation, \\
\hline Tetragonal, $P 4_{1} 2_{1} 2$ (No. 92) & $\mu=0.659 \mathrm{~mm}^{-1}$ \\
\hline $\mathrm{a}=\mathrm{b}=9.3574(2) \AA$ & $\mathrm{T}=291(2) \mathrm{K}$ \\
\hline $\mathrm{c}=45.6369(9) \AA$ & colourless plate \\
\hline $\mathrm{V}=3996.01(14) \AA^{3}$ & $0.5 \times 0.3 \times 0.2 \mathrm{~mm}$ \\
\hline \multicolumn{2}{|l|}{ Data collection } \\
\hline $\begin{array}{l}\text { Bruker SMART APEX II CCD } \\
\text { diffractometer }\end{array}$ & 3549 reflections with $I>2 \sigma(I)$ \\
\hline 37069 measured reflections & $\mathrm{R}_{\mathrm{int}}=0.0308$ \\
\hline \multicolumn{2}{|l|}{3644 independent reflections } \\
\hline \multicolumn{2}{|l|}{ Refinement } \\
\hline $\begin{array}{l}\mathrm{R}\left[\left(F^{2}>2 \sigma\left(F^{2}\right)\right]=0.0485\right. \\
\mathrm{wR}\left(F^{2}\right)=0.1529 \\
\mathrm{~S}=1.061 \\
3644 \text { reflections }\end{array}$ & $\begin{array}{l}255 \text { parameters } \\
\Delta \rho_{\max }=0.41 \mathrm{e} \AA^{-3} \\
\Delta \rho_{\min }=-0.18 \text { e } \AA^{-3}\end{array}$ \\
\hline
\end{tabular}

\section{RESULTS AND DISCUSSION}

The title compound (1) crystallizes in the non-centrosymmetric space group $P 4,2,2$ (No. 92), with one crystallographically independent molecule in the asymmetric unit. The core of the molecule consists of three fused rings, a cyclohexane ring $\boldsymbol{a}$, a five-membered pyrrolidine ring $\boldsymbol{b}$ and a six-membered diketopiperazine ring $c$, resulting in a rigid structure. The rest of the molecule is completed by disordered terminal methyl and ethyl groups of alkyl chains, which exist in two equally occupied conformations. Ring $\boldsymbol{a}(\mathrm{C} 3-\mathrm{C} 8)$ adopts a slightly deformed chair conformation as indicated by the Cremer and Pople puckering ${ }^{19}$ parameters, having a total puckering amplitude Q of $0.527(3) \AA$ with $\varphi=2.6(12)$ and $\theta=165.9(3)^{\circ}$. Ring $\boldsymbol{b}(\mathrm{N} 1 / \mathrm{C} 1-\mathrm{C} 3 / \mathrm{C} 8)$ adopts a slightly deformed half-chair conformation. Its total puckering amplitude $\mathrm{Q}$ is $0.399(2)$ $\AA$ and $\varphi=276.0(3)^{\circ}$. The diketopiperazine ring $c$ (N1/C1-C15/N2/C9-C10) is in a boat conformation with puckering amplitude $\mathrm{Q}=0.584(2) \AA, \varphi=60.9(2)$ and $\theta=92.2(2)^{\circ}$. The two oxygen atoms of carbonyl groups (O1) and (O4) lie on the same side of the pyrrolidine ring. Selected bond lengths and angles with their estimated standard deviations are given in Table 2. 


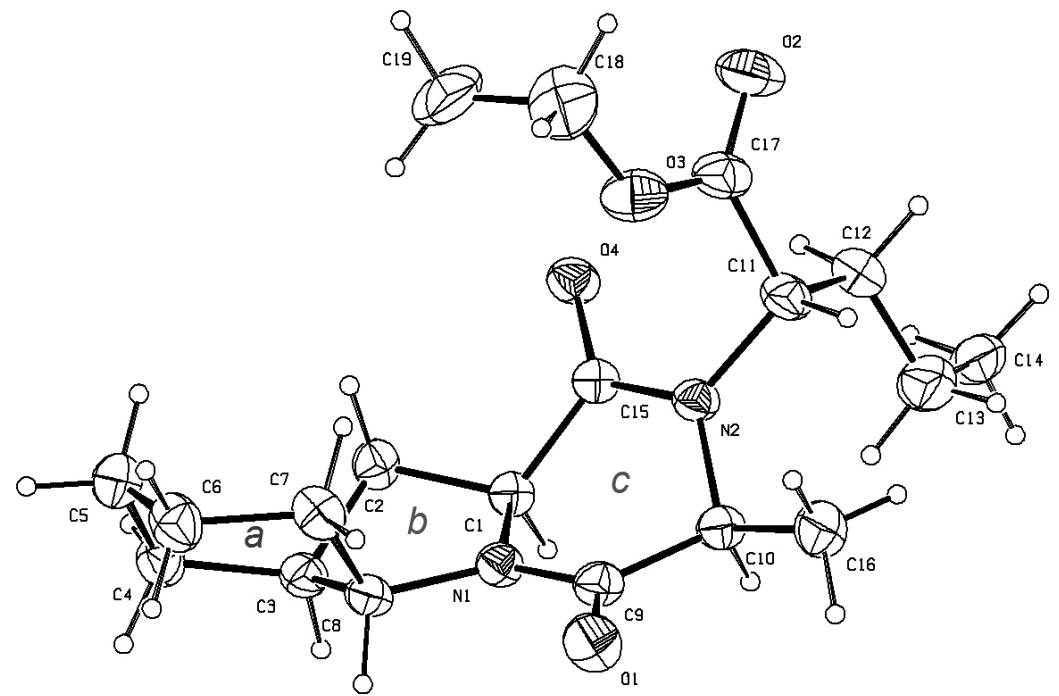

Figure 1. A view of the asymmetric unit of $\mathbf{1}$ showing the molecule and atom numbering scheme. Disorder was omitted for clarity.

Table 2. Selected geometric parameters: bond lengths $[\AA]$, bond angles and torsion angles $\left[{ }^{\circ}\right]$.

\begin{tabular}{|c|c|c|c|c|c|}
\hline & & & & \\
\hline O1-C9 & $1.212(3)$ & C9-C10-C16 & $110.28(19)$ & C1-N1-C9-O1 & $-179.19(19)$ \\
\hline O2-C17 & $1.207(4)$ & N2-C11-C17 & $111.2(2)$ & C9-N1-C1-C15 & $-41.0(2)$ \\
\hline O3-C17 & $1.329(4)$ & C1-N1-C8 & $112.86(15)$ & C8-N1-C1-C15 & $131.98(16)$ \\
\hline O4-C15 & $1.220(2)$ & C1-N1-C9 & $121.73(17)$ & C8-N1-C9-C10 & $-172.70(17)$ \\
\hline N1-C1 & $1.469(3)$ & C8-N1-C9 & $124.99(18)$ & C15-N2-C10-C16 & $-168.3(2)$ \\
\hline N1-C9 & $1.344(3)$ & C10-N2-C11 & $122.44(17)$ & C10-N2-C15-O4 & $-176.59(19)$ \\
\hline N2-C11 & $1.471(3)$ & C10-N2-C15 & $120.28(16)$ & C10-N2-C11-C17 & $-135.7(2)$ \\
\hline N2-C15 & $1.339(3)$ & C11-N2-C15 & $116.70(17)$ & C11-N2-C10-C9 & $144.7(2)$ \\
\hline C1-C15 & $1.517(3)$ & N1-C1-C15 & $110.72(15)$ & C11-N2-C15-C1 & $174.66(18)$ \\
\hline C9-C10 & $1.530(3)$ & O4-C15-N2 & $123.44(18)$ & N1-C1-C15-O4 & $-141.46(19)$ \\
\hline C10-C16 & $1.513(3)$ & O4-C15-C1 & $121.72(17)$ & N1-C1-C15-N2 & $38.8(2)$ \\
\hline C11-C17 & $1.511(4)$ & N2-C15-C1 & $114.84(16)$ & O1-C9-C10-N2 & $-139.4(2)$ \\
\hline & & O2-C17-O3 & $123.9(3)$ & N1-C9-C10-C16 & $168.10(19)$ \\
\hline & & O2-C17-C11 & $124.8(3)$ & N1-C9-C10-N2 & $42.0(2)$ \\
\hline & & O3-C17-C11 & $111.2(2)$ & N2-C11-C17-O2 & $-143.2(3)$ \\
\hline & & O1-C9-N1 & $123.5(2)$ & N2-C11-C17-O3 & $40.5(3)$ \\
\hline
\end{tabular}

A similar geometry is observed in $\left(3 S-\left(2\left(R^{*}\right), 3 \alpha, 5 \alpha \beta, 9 \alpha \beta, 10 \alpha \beta\right)\right)$ decahydro-3-methyl-1,4-dioxo- $\alpha$-(2-phenylethyl)pyrazino(1,2- $\alpha$ )indole$2(1 \mathrm{H})$-acetic acid ethyl ester methanol solvate $(\mathbf{2})$, which was obtained by cyclization of an other angiotensin-converting enzyme inhibitor - indolapril. ${ }^{20}$ The slight difference is visible from superposition of the two structures (Figure 2).

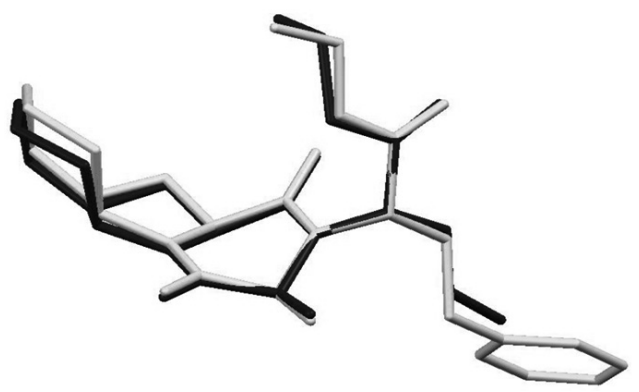

Figure 2. Superposition of molecules of known cyclization products of ACE inhibitors, the title compound $\mathbf{1}$ (black) and that of indolapril $\mathbf{2}$ (grey).

The crystal packing of (1) shows two weak intermolecular C-H..... contacts (Table 3), C10-H10 $\mathrm{O} 4[1 / 2-\mathrm{x},-1 / 2+\mathrm{y}]$ and $\mathrm{C} 19 \mathrm{~A}-\mathrm{H} 19 \mathrm{C} \cdots \mathrm{O} 1[\mathrm{x}, 1+\mathrm{y}, \mathrm{z}]$ which link molecules into 5- and 10-membered chains, respectively, with graph-set notations $C(5), C(10)$ and 18 -membered rings as viewed along the $a$-axis (Figure 3). ${ }^{21}$

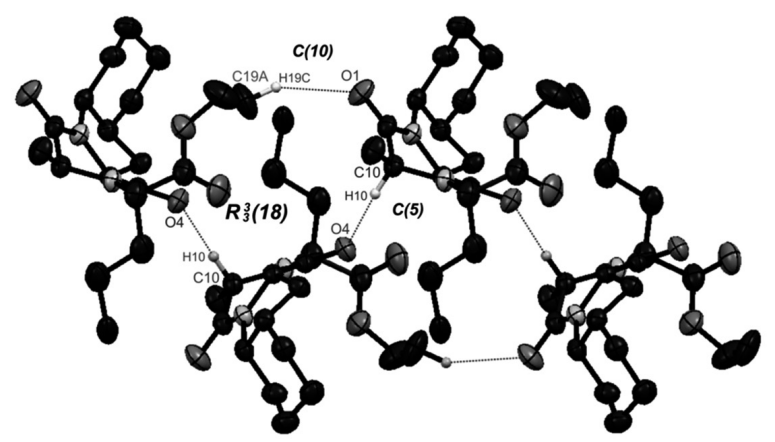

Figure 3. A packing view of $\mathbf{1}$ in the crystal: the intermolecular $\mathrm{C}-\mathrm{H} \cdots \mathrm{O}$ contacts forming infinite chains running along the [100] direction. Disordered atoms have been omitted for clarity. 
Table 3. Intermolecular contacts $\left(\AA,{ }^{\circ}\right)$.

\begin{tabular}{|l|c|c|c|c|}
\hline \multicolumn{1}{|c|}{$\mathrm{D}-\mathrm{X} \ldots \mathrm{A}$} & $\mathrm{d}(\mathrm{D}-\mathrm{X})$ & $\mathrm{d}(\mathrm{X} \cdots \mathrm{A})$ & $\mathrm{d}(\mathrm{D} \cdots \mathrm{A})$ & $<(\mathrm{DXA})$ \\
\hline $\mathrm{C} 10-\mathrm{H} 10 \cdots 4^{\mathrm{i}}$ & 0.98 & 2.34 & $3.267(3)$ & 157 \\
\hline $\mathrm{C} 19 \mathrm{~A}-\mathrm{H} 19 \mathrm{C} \cdots 1^{\mathrm{ii}}$ & 0.96 & 2.41 & $3.284(10)$ & 151 \\
\hline
\end{tabular}

Symmetry codes: (i) $1 / 2-x,-1 / 2+y, 1 / 4-z$, (ii) $x, 1+y, z$.

Supplementary Information: Crystallographic data for the structural analysis have been deposited in the Cambridge Crystallographic Data Centre CCDC 853460. Data Acquisition - the Cambridge Crystallographic Data Centre deposit@ccdc.cam.ac.uk Telephone: (44) 01223762910 Facsimile: (44) 01223336033 Postal Address: CCDC, 12 Union Road, CAMBRIDGE CB2 1EZ, UK (http://www.ccdc.cam.ac.uk/).

\section{REFERENCES}

1.- R. Ferrari, European Heart Journal Supplements, G13, 10 (2008)

2.- R. Ferrari, Expert Review of Cardiovascular Therapy 3, 15 (2005).

3.- J.J. Brugts, Tailored-therapy of ACE-inhibitors in Coronary Artery Diseas, 26-27 (2010).

4.- R. Ferrari, G. Pasanisi, P. Notarstefano, G. Campo, E. Gardini, C. Ceconi, Am. J. Hypertens. 18, 142S (2005).

5.- Patent No JP11206850 (A) (1998).

6.- Patent No A61K31/198 (2002).

7.- M. Vincent, B. Marchand, G. Remond, Drug Des. Discov. 9, 11 (1992).

8.- C. Pascard, J. Guilhem, V. M. Remond, G. Portevin, B. Laubie, J. Med. Chem. 34, 663 (1991).

9.- J. Bojarska, W. Manivkiewicz, L. Sierrón, P. Kopczacki, K. Walczyriskin, M. Remko, Acta Cryst. c8, 0443 (2012).

10.- M. Remko, J. Bojarska, P. Ježko, A. Olczak, L. Sieroń, W. Maniukiewicz, J. Mol. Struct. 3, 101 (2011).

11.- B.N. Roy, G.P. Singh, H.M. Godbole, S.P. Nehate, Indian J. of Pharm. Sciences 71, 395 (2009).

12.- D.A. Williams, W.O. Foye, T.L. Lemke, Foye's principles of medicinal chemistry, Lippincott Williams \& Wilkins, 5-th Ed., p. 745 (2002).

13.- G.M. Sheldrick, SADABS Ver. 2.10, University of Gottingen, Germany (2003).

14.- Bruker (2002). SMART. Ver. 5. 630 for WNT/2000.
15.- Bruker AXS Inc., Madison, Wisconsin, USA; Bruker. SAINT-Plus (Ver. 6.45) and SHELXTL (Ver.6.14). Bruker AXS Inc., Madison, Wisconsin, USA (2003).

16.- D. Nasipuri; The stereochemistry of organic compounds: principles and applications, New Age International, p. 36 (1994).

17.- I.J. Bruno, J.C. Cole, P.R. Edgington, M. Kessler, C.F. Macrae, P. McCabe, J. Pearson, R. Taylor, Acta Cryst. B58, 389 (2002).

18.- A.L. Spek, Acta Cryst. D65, 148 (2009).

19.- D. Cremer, J.A. Pople, J. Am. Chem. Soc. 97, 1354 (1975).

20.- C.J. Blankley, J.S. Kaltenbronn, D.E. DeJohn, A. Werner, L.R. Bennett, G. Bobowski, U. Krolls, D.R. Johnson, W.M. Pearlman, M.L. HoefIe, A.D. Essenburg, D.M. Cohen, and H. R. Kaplan, J. Med. Chem. 30, 1987 (1992).

21.- M. Etter, Acc. Chem. Res. 23, 120 (1990). 
J. Chil. Chem. Soc., 58, Nº 1 (2013) 